\title{
UNIVERSIDADE E DEMOCRACIA: PARA QUÊ? PARA QUEM?
}

\author{
Leonardo Nolasco-Silva ${ }^{(*)}$ \\ Adelia Miglievich Ribeiro ${ }^{(* *)}$
}

Este dossiê é, para nós (os organizadores), um gesto de resistência. É uma ação conjunta em torno de uma causa que nos é cara e, mais que nunca, necessária: a universidade. Combalida, perseguida, tratada como inimiga nos últimos tempos. A universidade pública tem sido alinhavada com a palavra crise. Amalgamada. Crise de legitimidade, crise de autonomia, crise política, crise de hegemonia, crise intelectual e tantas outras nomenclaturas negativas que podemos pinçar em textos de Darcy Ribeiro (1975) e Boaventura de Sousa Santos (2005) - ambos presentes, com estes conceitos, entre as referências dos autores que compõem o dossiê.

Darcy, aliás, idealizador de importantes universidades brasileiras (não somente), foi quem nos inspirou nesta empreitada: “Cumpre perguntar: pode a Universidade converter-se em um instrumento de mudança intencional de nossas sociedades?” (RIBEIRO, 1991, p. 22). Tendo esta questão como guia, traçamos um mapa temático das paisagens que julgamos oportuno exibir: a universidade no pensamento social brasileiro; a universidade como política pública; a universidade e o desenvolvimento regional e nacional; a universidade e a integração dos países latinoamericanos; a universidade e a EaD; a universidade e as políticas afirmativas; a universidade e as sociabilidades juvenis; a universidade e as novas artes de ensinar; a universidade em outros contextos nacionais periféricos. Desta maneira, os artigos selecionados cumprem este roteiro e, a partir de múltiplas possibilidades de interpretação, tensionam em seus campos a relação entre a universidade e a democracia, sublinhando a pertinência de uma para a efetivação da outra.

O conjunto de textos aqui reunidos está mais para conversa estendida. Um artigo vai chamando o outro, abrindo janelas, tecendo "fuxicos" - colcha de retalhos -, construindo pontes, desafiando pontos de vista. Em comum, algumas ideias partilhadas: a universidade é espaço/tempo de produção e difusão dos saberes, é ponto de partida para novas possibilidades de vida; é lugar de luta política e de disputa das narrativas; é a tensão entre o pensamento hegemônico e o devir-

\footnotetext{
${ }^{(*)}$ Professor adjunto e coordenador de comunicação social da Faculdade de Educação da Universidade do Estado do Rio de Janeiro. Coordenador da área de Tecnologias do Departamento de Estudos Aplicados ao Ensino. E-mail: leonolascosilva@gmail.com.

${ }^{(* *)}$ Professora adjunta do Departamento de Ciências Sociais da Universidade Federal do Espírito Santo (Ufes) e docente permanente do PPG Ciências Sociais e do PPG Letras. PQ-CNPq, nível 2. Pesquisadora Fapes. E-mail: miglievich@pq.cnpq.br.
} 
conhecimento, anti-hegemônico; é o embate entre a tradição seletiva e a atualidade; é cenário da luta de classes; é uma promessa de inclusão que não inclui todo mundo; é a contestação da universalidade;é pedra e caminho para anseios privatistas e neoliberais, mas também é a diversidade possível em cada tempo histórico (e a tentativa de alargar o universal em nome do pluriversal e das histórias partilhadas). Puxando pela memória, a universidade uniu a gente - os organizadores do dossiê. Uma, professora; o outro, seu aluno, nos idos do ano 2000. Dezenove anos depois, já colegas de profissão, indagamos à universidade que nos juntou: para que ela serve? A quem ela serve? A quem estamos servindo?

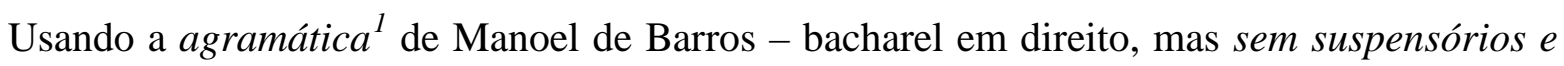
ademanes - podemos dizer que a universidade está de cabeça para baixo e nós precisamos deslêla. A configuração da universidade mudou, ela ganhou novos públicos, ao mesmo tempo em que, provavelmente não por coincidência, viu seus laços com a sociedade se transformar. Em um curto espaço de tempo, deixou de ser horizonte de (auto)realização para se converter em ameaça. Acusada de propagar o que chamam - sem maiores explicações e para susto de seus estudiosos - de “marxismo cultural”, viu o nome do alfabetizador popular mundialmente consagrado, o humanista e brasileiro Paulo Freire, ser alçado ao posto de “inimigo nacional”. Segundo matéria publicada na Folha de São Paulo, o presidente eleito - Jair Bolsonaro - acredita que “os ensinamentos marxistas de Paulo Freire atrapalham o desenvolvimento dos alunos”. E promete “entrar com um lançachamas no MEC e tirar o Paulo Freire lá de dentro”². A ameaça de expulsão, entretanto, não se restringe aos clássicos da teoria educacional brasileira, mas também aos desvalidos a quem tais nomes e teses davam esperança de uma existência mais plena. Nas palavras do atual ministro da Educação - Ricardo Vélez Rodríguez - “As universidades devem ficar reservadas para uma elite intelectual, que não é a mesma elite econômica” ${ }^{3}$. Cabe-nos perguntar se a elite econômica abriria mão de se reproduzir como “organizadora da cultura”. Com Manoel, pensamos: o Estado desbrincou de nós. Os vidros de arnica já não curam as nossas machucaduras. O dia envelheceu

\footnotetext{
${ }^{1}$ As palavras e expressões em itálico são derivadas da vasta obra de Manoel de Barros. Não citaremos as páginas ou os livros, pois são construções recorrentes do autor. Os usos que fizemos são livres inspirações, sem ligação direta com o contexto original da obra do poeta.

2 Disponível em: <https://www1.folha.uol.com.br/educacao/2018/10/na-mira-de-bolsonaro-paulo-freire-nao-esta-nocurriculo-mas-e-referencia-em-escolas.shtml>. Acesso em: 7 fev. 2019.

3 Disponível em: <https://catracalivre.com.br/cidadania/universidade-nao-e-para-todos-diz-ministro-da-educacao/> . Acesso em: 7 fev. 2019.
} 
para a democracia. E é preciso estar atento e forte ${ }^{4}$. E é preciso dizer aquilo que nos assombra. E diremos cada vez mais alto e muito bem acompanhados.

Comecemos pelo fim, pela entrevista que nos serviu de lição - daquelas que não esqueceremos. Conversamos com Gaudêncio Frigotto, professor e pesquisador da Universidade do Estado do Rio de Janeiro (Uerj). Frigotto tem pensado sobre o fortalecimento de práticas fascistas em nosso cotidiano, sobretudo no âmbito da educação, cujo expoente mais visível é o programa Escola “sem” Partido. Nosso encontro com ele, demorado e agradável, aconteceu no dia seguinte ao primeiro turno da eleição presidencial de 2018. Nas colocações do nosso entrevistado, então, haverá menções a outros cenários possíveis, mas a já certeza de que quaisquer deles colocavam em xeque as conquistas históricas do povo brasileiro em sua frágil redemocratização. Gaudêncio reconhece que a universidade, sobretudo nos anos recentes, perdeu espaço para outros produtores de narrativas, fechando-se em si mesma, recusando-se, muitas vezes, a se abrir para os sujeitos há muito ausentes da vida universitária. Talvez precisemos, como sugere o poeta cuiabano, desaprender oito horas por dia porque isso nos ensina os princípios.Desacostumar a palavra acostumada. Entrar na universidade e alcançar os deslimites do Ser. Descobrir que todos os caminhos levam à ignorância. Ocupar muito de nós com o nosso desconhecer. Tirar da natureza as naturalidades e tirar da universidade as universalidades. Saber o valor das coisas imprestáveis. Não deixar a universidade virar lacuna de gente.

A prosa poética de Manoel conversa bem com os escritos e os fazimentos de Darcy Ribeiro. Se o poeta pantaneiro inventa uma língua nacional, mais afeita à gente simples, o intelectual público de Montes Claros defende o desenvolvimento de um pensamento nacional que se debruce sobre os nossos problemas, abdicando das soluções importadas ou dos modelos explicativos concebidos para contextos outros. A contribuição de Darcy para o campo da educação é de uma sensatez que aumenta os absurdos. Potente, provocador, original. Homem do seu tempo e à frente dele, Darcy é o centro da resenha que Estevão Rafael Fernandes, da Universidade Federal de Rondônia, faz do livro organizado por Lúcia Velloso Maurício - Darcy Ribeiro: Educação como prioridade. O livro é formado por "27 capítulos nos quais transborda Brasil e brasilidade, hoje tão raros à nossa elite intelectual”. Tendo vivenciado a UnB, o resenhista permite-se contagiar pela paixão de Darcy Ribeiro e registra a carência em nossa comunidade científica de mentes e corpos que, para além das metas de produtividade que impõem lamentavelmente a lógica empresarial e mercadológica na universidade pública, sublinha a prioridade de fazer da educação instrumento de superação das

\footnotetext{
${ }^{4}$ Verso da canção Divino, Maravilhoso, de 1968. Composição de Caetano Veloso e Gilberto Gil, gravada por Gal Costa.
} 
abissais desigualdades sociais que ferem de morte o povo brasileiro. Nos fundos do quintal era muito riquíssimo o nosso dessaber.

O artigo que abre o dossiê, de Luís Rodrigues - "Potencial transformador do ensino superior em Cabo Verde” - oferece um panorama relevante sobre a história recentíssima do ensino superior num país irmão, na África, de colonização portuguesa, e demonstra o duro combate dos caboverdianos para exercer o direito de acesso de sua população à universidade. Mundialmente, as universidades servem, nos contextos nacionais, para a produção de valores e legitimação social, para a seleção das elites dominantes e para a formação da força de trabalho.Neste caso, a democratização do ensino superior em Cabo Verde enfrenta como obstáculos a ainda prevalência da iniciativa privada; também, a tensão entre a melhoria da qualidade da oferta educacional e a ainda subutilização dos novos perfis profissionais em sua sociedade; por fim, a problemática do domínio da língua portuguesa, privilégio das classes já mais favorecidas. O manejo ou não do idioma do colonizador é critério de definição de quem será a elite pensante da nação, convertendo-se em fator de cisão social. Há um dado ainda peculiarmente curioso: as mulheres são a maioria estudantil, o que pode, para o autor, indicar uma mudança de paradigma a curto/médio prazo, através do empoderamento feminino.

Assinado por Amurabi Oliveira, da Universidade Federal de Santa Catarina - “O ensino universitário no pensamento de Gilberto Freyre” - encontra no autor de Sobrados e Mucambos um caminho teórico para pensar a universidade ontem e hoje. O clássico do Pensamento Social Brasileiro não costuma ter seu nome ligado à educação e, sobretudo, por conta de uma de suas feições, inegável, esteve sob severa crítica no bojo das lutas antirracistas no Brasil. Porém, neste ensaio, como frisa seu autor informando estar apenas no início de um trançado, Oliveira exercita o ofício do pesquisador e nos apresenta outro Freyre, o jovem acadêmico que sai de Pernambuco para Columbia, profundamente enraizado em sua região. A erudição intelectual não poderia apartar teoria e experiência. E, como também defendia Darcy, argumentava que o conhecimento da região e dos problemas locais possibilitaria o desenvolvimento de um ensino que não fosse "livresco". Freyre propôs pensar um modelo de universidade inter-regional, no qual o nacional e o regional não fossem postos como binômios opostos, mas sim como polos articulados fundamentais para o desenvolvimento de um projeto de nação. Ao mesmo tempo, é bem-vinda sua preocupação com o que contemporaneamente denominamos transdisciplinaridade.

Projeto de nação e universidade estão na pauta do artigo assinado por Sílvio Cláudio Souza e Carla Zottolo Villanova - “A importância do pensamento e dos fazimentos do intelectual Darcy Ribeiro”. Como já apontamos, Darcy acredita na universidade comprometida com o 
desenvolvimento de um pensamento nacional capaz de indicar caminhos para a superação dos problemas do país. Neste texto, os autores recuperam a trajetória política e intelectual de Darcy, focando em sua concepção de universidade necessária - uma universidade-instrumento,capaz de propor um diagnóstico honesto das causas dos grandes problemas nacionais, destacando aqui a condenação ao “atraso” em que vive parcela majoritária da população, visando à consolidação de um Estado nacional que represente seu povo, promotor da inclusão de todos, protagonista, enfim, da construção democrática onde os governos não façam essas coisinhas sem santidade.

Por falar em fazimentos - nome dado por Darcy ao seu pensamento-ação - o texto de Glauber Rabelo Matias - "De volta ao "terceiro milênio”: círculos sociais na construção da UENF em Campos dos Goytacazes” - narra o processo de elaboração e implementação da Universidade Estadual do Norte Fluminense Darcy Ribeiro (Uenf), em Campos dos Goytacazes, revelando a complexa trama que, por décadas, alimentou o sonho de uma universidade para o interior do Estado, tendo como suporte teórico o conceito de “círculos sociais”, do sociólogo Georg Simmel. A reconstituição histórica dos fatos - por meio de entrevistas e consulta a documentos - permitiu ao pesquisador minucioso perceber os meandros do jogo político local, tensões, antagonismos, alianças. Agentes locais e não-locais souberam se unir, contudo, mesmo quando em oposição. Uma emenda popular extraordinária insere na Constituição do Estado do Rio de Janeiro o imperativo de se fazer uma universidade pública. Mas, para quê? Para quem? A luta travada por Darcy Ribeiro não é menos extraordinária. A visualização da história como luta cultural é pujante em seu artigo.

Nessa trilha que liga a universidade a um projeto de desenvolvimento nacional e regional, o artigo “A UNILA e a integração: miragem latina, horizonte neoliberal ou disputas contínuas”, de autoria de Roberta Traspadini e Leo Alves da Silva, problematiza - a partir de uma perspectiva histórico-crítica, marxiana - a efetiva contribuição da Universidade Federal da Integração LatinoAmericana para a solidariedade na periferia a partir do conhecimento. As perguntas disparadoras do artigo são: Como nasce e se desenvolve a UNILA? Qual o contexto de política externa e nacional no qual ela está inserida? Os autores, ao tecerem os fios da história recente da universidade, apontam as contradições entre o ideal de integração pelo conhecimento e areal submissão à teoria do capital humano, argumentando que a promessa de inovação no campo progressista pode ter sucumbido ao discurso neoliberal, formador de mão de obra facilmente substituível em mercados do "terceiro mundo".

A crítica ao neoliberalismo aplicado à educação também dá o tom do artigo de Vittorio Lo Bianco e Lia Faria - “A experiência do consórcio Cederj e a democratização do acesso ao ensino superior no Estado do Rio de Janeiro”. Os autores refletem sobre o lugar da modalidade 'Educação 
a Distância' na ampliação da oferta educacional de nível superior no território fluminense, analisando a trajetória do Centro de Educação a Distância do Estado do Rio de Janeiro (Cederj) e sua conexão com o pensamento-ação de Darcy Ribeiro - entusiasta da EaD num tempo em que a modalidade ainda não era considerada no âmbito das políticas públicas de educação. Ao traçar as linhas gerais dos caminhos e descaminhos do Cederj, indagam sobre os desafios que se apresentam e sublinham sua potência enquanto via de acesso ao ensino superior por milhares de estudantes. Para tanto, Lo Bianco e Faria não se limitam aos documentos oficiais que narram a história do Consórcio. Eles ampliam as fontes de produção de dados, incluindo conversas com docentes e discentes que compõem o Cederj, entrevistas com atores que participaram de sua fundação, além de netnografia.

Se a ampliação do acesso oportunizada pela Ead muda a configuração quantitativa do perfil universitário brasileiro, as políticas de ação afirmativa contribuem para outra transformação, mais visível e propensa ao conflito.O artigo de Andrea Bayerl Mongim e Osvaldo Martins de Oliveira, da Universidade Federal do Espírito Santo - "Entre comemorações, tensões e constrangimentos: ingresso na universidade pelo sistema de cotas” - analisa o processo de ingresso e de permanência na universidade de discentes cotistas, destacando desafios, tensões e constrangimentos. Trata-se de estudo etnográfico, com utilização de entrevistas de "narrativas de vida”. Os autores argumentam que o ingresso na universidade constitui-se em motivo de comemoração para os discentes que, em geral, reconhecem a importância do sistema de cotas para esse fim. No entanto, além das dificuldades financeiras, convivem cotidianamente com episódios de estigmatização e segregação. Parte dos estudantes busca superar tais desafios através da organização coletiva e da denúncia de toda forma de discriminação. Outros, internalizam a “ética do sacrifício pessoal” entrelaçando-o, como diria Mauss, à dádiva. Assim, os pesquisadores expõem o quanto o predomínio de concepções e práticas hierarquizantes e racistas ainda são obstáculos a uma universidade democrática. Sem as cotas, já reparamos, muitos jovens perderiam o poder de voar livres.

As condições materiais de permanência na universidade, sublinhadas no texto de Mongim e Oliveira, também serão destacadas por Manuela Blanc e Barbara Vitor de Aquino e Souza, no artigo “A potência da universidade como espaço de construção de si e de um agir sobre o mundo”. As autoras, partindo de dados primários produzidos em suas respectivas pesquisas, oferecem um panorama sobre o perfil do jovem universitário em duas realidades distintas - numa universidade pública em Campos dos Goytacazes e noutra privada, em Vila Velha, no Espírito Santo. No primeiro cenário, o destaque é para as formas de sociabilidade no cotidiano da universidade a partir do envolvimento com a pesquisa, do distanciamento da família e da relação com o auto sustento, 
baseado, sobretudo, nos programas de bolsas estudantis. No segundo cenário, a ênfase esteve no acompanhamento de estudantes que atuam nos coletivos universitários. A atuação política é percebida pelas estudantes como parte do seu processo de formação, fortalecendo o sentimento de pertencimento ao curso e de identificação com a futura profissão. Na universidade, outras subjetividades afloram e podem contestar a ordem que até então dispunha coisas e pessoas. Quem sabe, por isso, é tão temida? Porque o jovem é um ser imprestável para o silêncio.

A busca de um sentido para a vida a partir da universidade - e a construção de um sentido para a própria experiência universitária - é uma preocupação que se prolonga no artigo de Patrícia Lupion Torres, Rui Trindade e Virgínia Bastos Carneiro - “Autonomia discente na universidade: metodologias ativas e a cibercultura”. A renovação do perfil do aluno universitário, em face das mudanças de comportamentos e de valores da sociedade, demanda o desenvolvimento de novas práticas voltadas para a autonomia discente. A necessidade de transformação para uma atuação protagonista do estudante é ampliada de forma significativa a partir do aumento do uso de tecnologias digitais de informação e comunicação (TDICs) e de tecnologias móveis e sem fio (TMSF) que determinam, desde há muito, a organização social em redes, em outros tempos e espaços. Essas evoluções tecnológicas podem penetrar em toda a estrutura social e vir a ter um papel significativo na construção de sociedades mais democráticas. O artigo, então, trata da autonomia discente,sob a lente do pragmatismo de John Dewey, de modo a problematizar as metodologias ativas no cenário educacional contemporâneo e na participação ativista em rede.

Ao apresentarmos brevemente os textos que compõem o dossiê “Universidade e Democracia chamamos” o leitor a mergulhar em cada um dos saberes aqui produzidos e deles retirar um sentido sobre a universidade e sobre a democracia. Temos a consciência que, no Brasil, a democracia é mais falta do que presença. Foram muitos os anos de “exceção" e foram vários os nossos golpes de Estado. A democracia brasileira é jovem e frágil. Muito mais forte é a marca da escravidão, na história do Brasil, que ainda hoje segrega, diferencia, mata e inviabiliza a vida dos que não são brancos nem têm posses. E o que pode fazer a universidade diante da cruel desigualdade na qual está inserida?

As Universidades que atuarem como simples guardiãs do saber tradicional só poderão sobreviver enquanto suas sociedades se mantiverem estagnadas. Entretanto, quando estas começarem a mudar, a Universidade também se verá desafiada a alterar suas formas para servir às novas forças sociais (RIBEIRO, 1991, p.173).

As coisas começaram a mudar. A universidade está sendo desafiada a alterar suas formas para servir às novas forças sociais.O reacionarismo era esperado como contrapartida. Agora, é a vez 
da resistência, como dissemos no início. Trata-se, como fez Manoel de Barros, de desaprender o aprendido, de buscar o criançamento das palavras, lá onde o verbo delira. Trata-se de desacostumar os velhos hábitos, de ressignificar as nossas significâncias, alargando o olhar dessas pessoas pouco favorecidas de horizontes. A universidade precisa deixar de ser essa senhora de nobrementes. Com pedaços de gente ela vai se montando um ser atônito. Queremos que ela cresça para passarinho. A universidade nos coisa. A universidade nos rã. A universidade nos árvore.

\section{REFERÊNCIAS}

BARROS, Manoel de. Biblioteca Manoel de Barros. São Paulo: LeYa, 2013. 18 volumes.

RIBEIRO, Darcy. A Universidade Necessária. 2. ed. Rio de Janeiro: Paz e Terra, 1975.

SANTOS, Boaventura de Sousa. A universidade no século XXI: para uma reforma democrática e emancipatória da universidade. 2. ed. São Paulo: Cortez, 2005. 